\title{
Metodologia para análise tecnológica em cristais de quartzo
}

\author{
Luis Felipe Bassi*
}

\begin{abstract}
BASSI, L.F. Metodologia para análise tecnológica em cristais de quartzo. R. Museu Arq.
\end{abstract} Etn., 25: 105-117, 2015.

Resumo: $\mathrm{O}$ tema deste artigo foi discutido na dissertação de mestrado sobre a análise tecnológica do cristal de quartzo proveniente do sítio arqueológico Bibocas II, em Jequitaí/MG (Bassi, 2012). Pela avaliação dos ângulos entre as facetas naturais do cristal, identificam-se elementos importantes dos processos de lascamento, de modo que o método proposto permite localizar a lasca no suporte/núcleo e mapear possíveis métodos de lascamento.

Palavras-chave: Tecnologia lítica. Cristal de quartzo. Métodos e técnicas de lascamento.

\section{Introdução}

$\mathrm{O}$ tema deste artigo foi discutido na dissertação de mestrado do autor (Bassi 2012), sobre o sítio arqueológico Bibocas II, localizado em Jequitaí-MG. O trabalho é fruto de pesquisas realizadas desde 2008 e financiadas pela FAPEMIG e pelo CNPq, em projetos coordenados pela Prof ${ }^{a}$ Dr $^{\mathrm{a}}$ Maria Jacqueline Rodet, do Setor de Arqueologia Pré-Histórica da UFMG.

Um artigo dedicado exclusivamente à análise de cristal de quartzo pretende questionar a simplicidade e a superficialidade com que este tema é geralmente tratado - quase sempre uma descrição de estigmas, apresentação morfológica e/ou análise estatística sem problemáticas definidas. O objetivo aqui é apresentar uma metodologia de análise baseada na identificação dos eixos do cristal pelas facetas naturais, o que permite levantar discussões sobre as sequências de lascamento, mesmo na falta de núcleos ou instrumentos.

Dessa forma, é possível analisar apenas lascas e distinguir sequências de cadeias operatórias específicas, desde que existam peças com

* CEARPH - UFMG facetas de cristal em quantidade suficiente. A análise das facetas permite identificar métodos de lascamento e formas de abordagem de cristais, ou seja, é possível discutir escolhas relativas a técnicas e modos de gestão dessa matéria-prima, como a preferência do primeiro golpe para abertura de um plano de percussão, controle volumétrico etc.

\section{Características do cristal de quartzo: considera- ções sobre cristalografia}

A cristalografia (ciência que estuda os cristais e as leis que governam seu crescimento, forma externa e estrutura interna) considera que a grande maioria dos cristais tem arranjo interno ordenado. Em condições ideais, assumem formas geométricas regulares (superfícies planas e lisa) (fig.1).

Podemos, assim, idealizar uma definição mais ampla de um cristal como um sólido homogêneo possuindo ordem interna tridimensional que, sob condições favoráveis, pode manifestar-se externamente por superfícies limitantes, planas e lisas (Dana e Hurlbut 1974: 4).

As características físicas e químicas dos cristais são constantes e podem ser tomadas como 


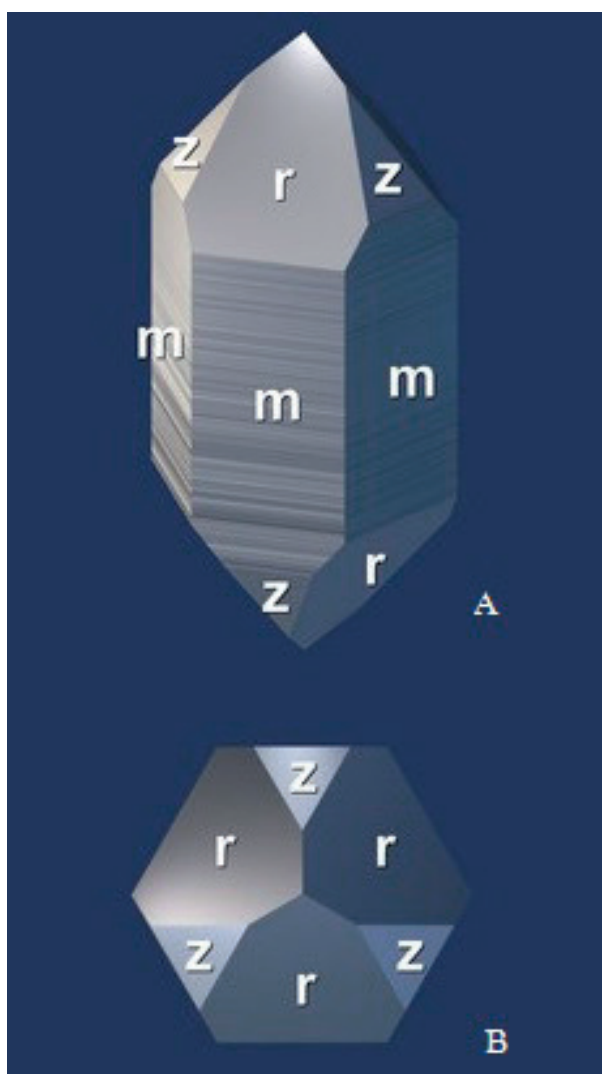

Fig. 1. As diferentes faces do cristal de quartzo, as quais se apresentam sempre desta maneira em minerais bem desenvolvidos, designadas por letras, onde: $\mathrm{m}$ - 6 faces do prisma hexagonal do corpo do cristal (A) apresentam estrias horizontais; $r$ - 3 faces maiores, mais ou menos triangulares, no ápice do cristal (B); e $z$ - 3 faces menores, geralmente triangulares, no ápice do cristal. (adaptado de: http://www.quartzpage.de/ crs_intro.html. Acesso em 19/04/2012).

referências para a análise tecnológica de peças lascadas. A forma mais recorrente do quartzo na coleção analisada é de prisma hexagonal hialino em posição primária. É um composto químico de pureza quase completa e de propriedades físicas constantes. Os cristais são quase sempre prismáticos, com facetas naturais que podem conter estrias (fig. 2A) transversais ao eixo longitudinal do prisma, o que permite identificar a orientação dos fragmentos e das lascas (eixo longitudinal e transversal do cristal).
Todo cristal apresenta facetas naturais que formam entre si ângulos com regularidade e constância (Lei de Steno), portanto, sempre com as mesmas medidas. Dessa forma, é possível aplicar metodologias da mineralogia e da cristalografia para extrair informações sobre a posição e a direção da lasca em relação ao cristal, seja no núcleo, no suporte ou em restos brutos de lascamento.

Desde que a estrutura interna de qualquer substância cristalina é constante e as faces do cristal têm relação definida com aquela estrutura, segue-se que as faces devem ter relação definida entre si. Este fato foi observado muito tempo atrás (1669) por Nicolaus Steno, que acentuou que os ângulos entre as faces correspondentes nos cristais de quartzo eram sempre os mesmos. Generalizamos hoje esta observação designando-a Lei de Steno da constância dos ângulos interfaciais, a qual afirma que os ângulos entre faces equivalentes de cristais da mesma substância, medidos à mesma temperatura, são constantes. Por essa razão, a morfologia cristalina é frequentemente instrumento valioso na identificação do mineral. Um cristal pode ser achado em cristais de tamanhos e formas largamente variados, mas os ângulos entre pares de faces correspondentes são sempre os mesmos (Dana, J. D.; Hurlbut C. S., 1974: 13).

Para medir os ângulos recorrentes em cristais, é necessário que exista uma aresta natural, formada pelo encontro de duas facetas. $\mathrm{O}$ instrumento que afere os ângulos recorrentes é o goniômetro de contato (fig. 3) e deve estar exatamente perpendicular à aresta medida, ou seja, é necessário identificar o eixo cristalográfico conforme a figura $2 \mathrm{~B}$ e a figura 3 .

As estrias de crescimento nas facetas de cristal (fig. 2A) são o indicador mais seguro do eixo cristalográfico, mas isso depende também de o fragmento de quartzo analisado remeter ao corpo ou ao ápice do cristal. Por isso, o melhor é conjugar o máximo de informações e aliar as facetas naturais às estrias de crescimento. 

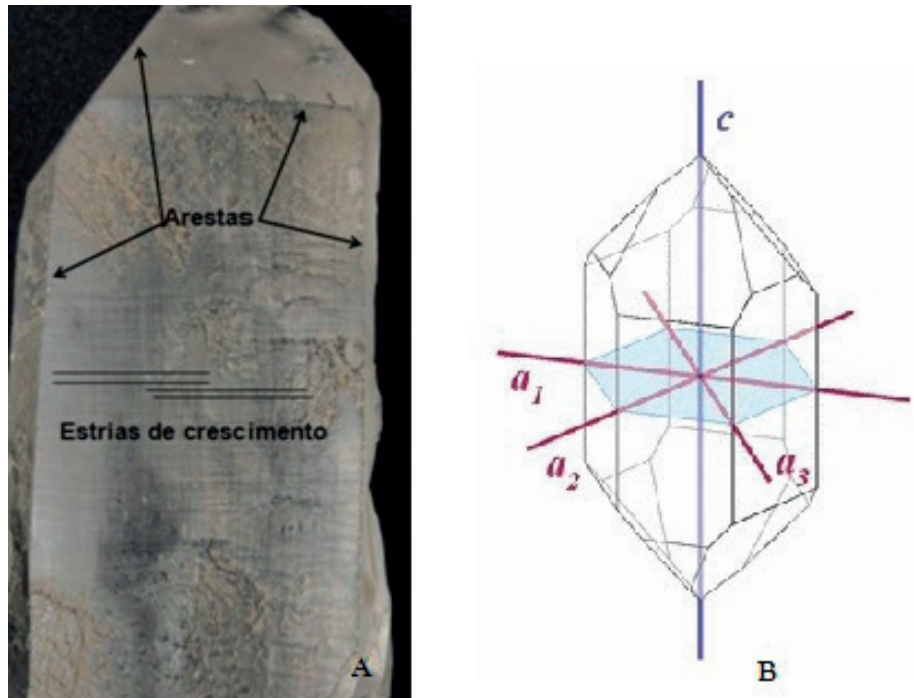

Fig. 2: Esquema básico para identificação e orientação do cristal de quartzo para tomada das medidas dos ângulos recorrentes. A: Arestas e estrias de crescimento do cristal, realçadas com grafite para melhorar a visibilidade. B: Eixos cristalográficos do cristal de quartzo (adaptado de http://www. quartzpage.de. Acesso em 19/04/2012).

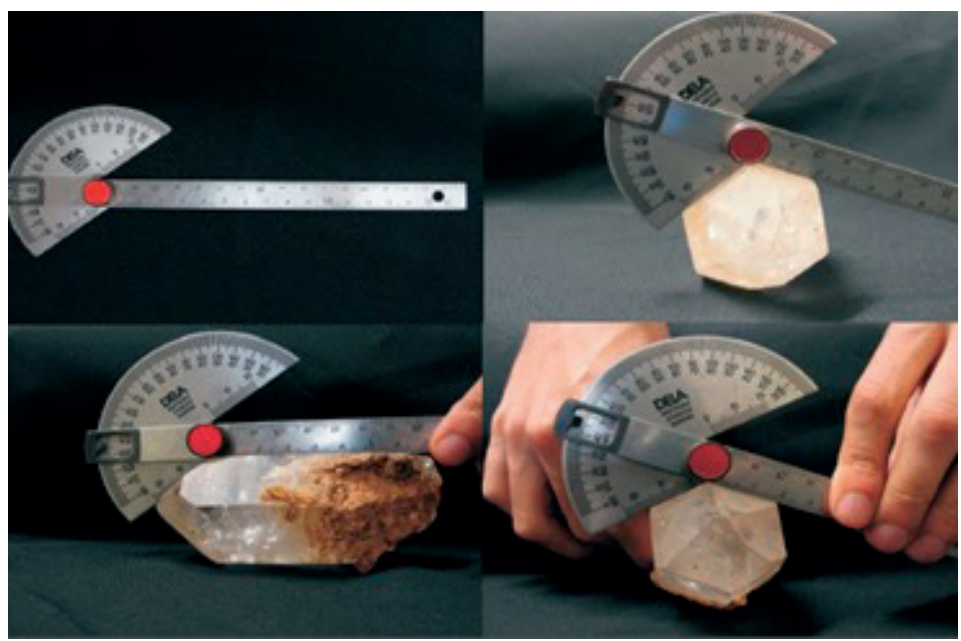

Fig. 3. Goniômetro de contato que mede arestas do cristal de quartzo. A posição da lâmina do goniômetro é sempre perpendicular à aresta a ser medida (Bassi, 2012)

É comum encontrar muitos cristais do mesmo mineral numa localidade, sendo que todos têm aparência idêntica. Mas esses cristais podem ter aparência inteiramente diferente, dependendo de seu hábito (fig. 4) Os cristais de quartzo têm ao menos oito hábitos, corres- pondentes às possíveis formas/formatos que o cristal pode assumir. Isso depende das condições no momento da formação, e o tipo mais comum é o de hábito normal ou prismático. Mesmo com aparências distintas, os ângulos correspondentes entre as facetas não mudam. 


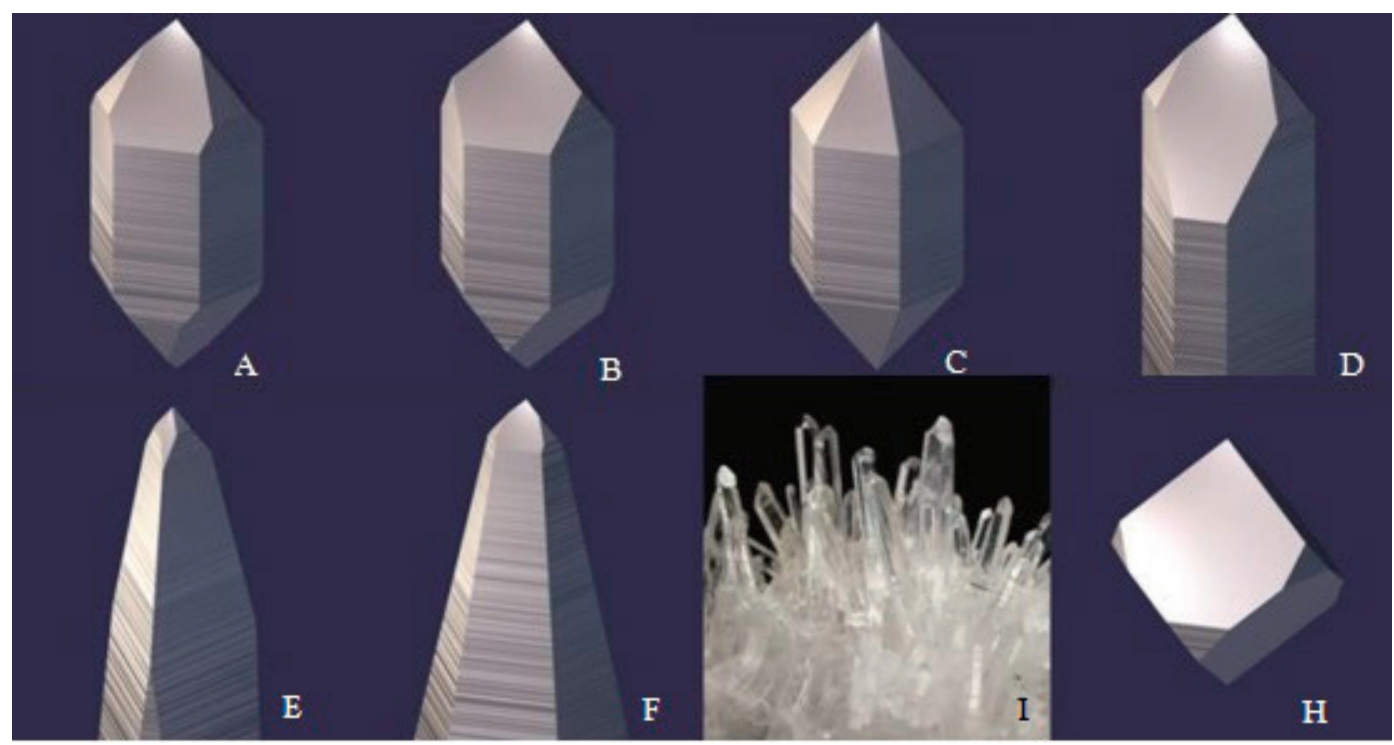

Fig. 4. Alguns possíveis hábitos do cristal de quartzo: A. normal ou prismático; B. trigonal; C. hexagonal; D. dauphine; F. muzo; G. tessin; H. agulha; I. cúbico ou pseudocúbico. Fonte: http://www.quartzpage.de. Acesso em 19/04/2012

Cristais de quartzo: elementos para reconhecer métodos de lascamento

Os ângulos identificados como recorrentes são: $120^{\circ}$ (corpo-corpo), $142^{\circ}$ (corpo-ápice), $134^{\circ}$ (ápice-ápice), $115^{\circ}$ entre facetas não consecutivas de corpo-ápice e $86^{\circ}$ para facetas não consecutivas de ápice (fig. 5). Esses ângulos foram medidos com um goniômetro de contato ${ }^{1}$ exatamente perpendicular à aresta medida. Ou seja, o cristal, ou o fragmento de cristal que se quer medir deve seguir seu eixo cristalográfico.

Portanto, os ângulos descritos acima foram usados como referência para determinar a localização da lasca no cristal, permitindo que se definisse a direção do golpe em relação ao núcleo ou suporte. Dessa forma, é preciso buscar a referência sempre na relação entre o eixo tecnológico da lasca e o eixo do cristal. Isso é possível pela relação entre talão e face inferior (interna) da lasca, da identificação das arestas naturais e/ou estrias de crescimento.

1 O único goniômetro de contato disponível era de metal, por isso foi necessário cobrir com uma fina fita plástica adesiva transparente o ponto de contato entre a peça e o instrumento de medição.
A análise conjunta desses elementos permite identificar a orientação do lascamento, tendo como referência o eixo cristalográfico do quartzo. Dessa forma, há a possibilidade de mapear escolhas e possíveis recorrências na maneira como essa matéria-prima foi gerida.

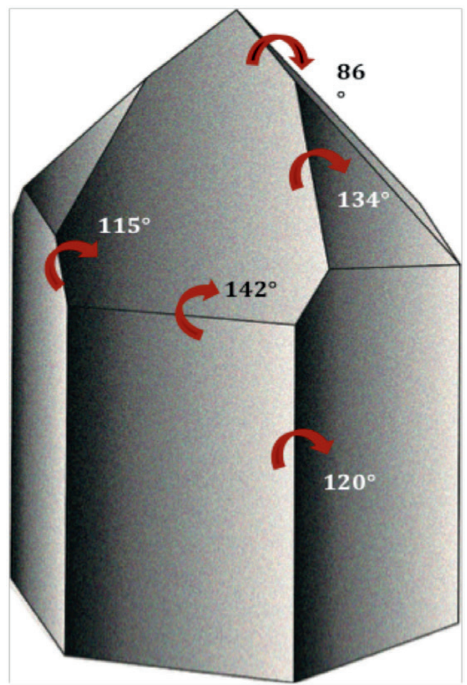

Fig. 5. Medidas dos ângulos recorrentes entre as facetas de cristal de quartzo (Bassi, 2012: 82). 


\section{Particularidades que confundem}

Há casos em que se encontram ângulos "desviantes", ou seja, ângulos que fogem muito do padrão identificado, e para isso há três possibilidades explicativas: a primeira é que se trate de um tipo de cristal de quartzo muito específico chamado de dupla terminação ${ }^{2}$; a segunda é que não se possam medir os ângulos entre as facetas perpendicularmente ao goniômetro, fornecendo uma medida falsa; a terceira é que existam cristais subidiomórficos ou subédricos ${ }^{3}$.

Há nas facetas naturais algumas marcas com regularidade e paralelismo parecidos com as estrias de crescimento, e isso pode prejudicar a identificação da orientação do cristal. Essas

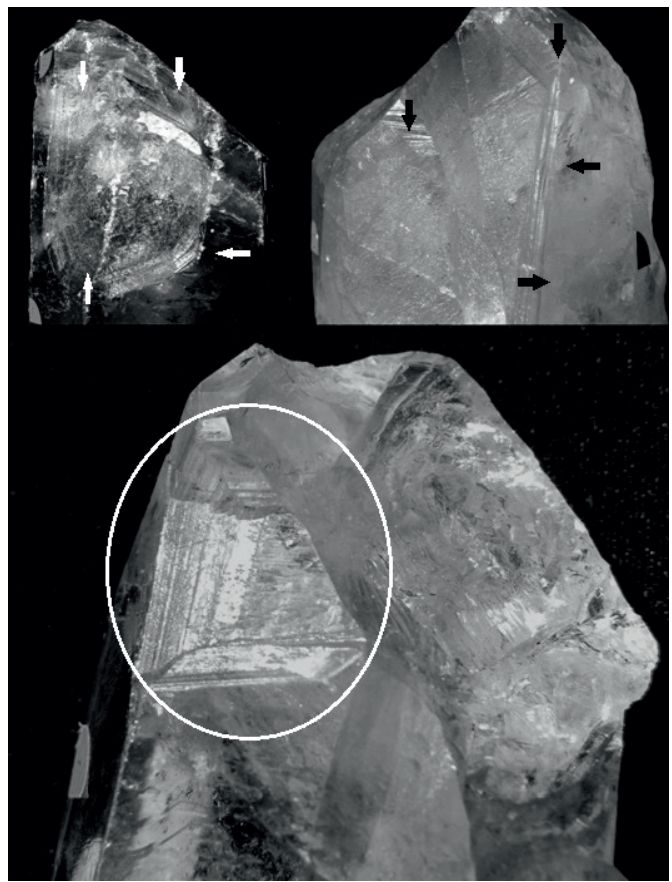

Fig. 6. Cristais de quartzo com marcas parecidas com estrias de crescimento, mas que não são indicadoras do eixo cristalográfico. Essas marcas são decorrentes do crescimento de cristais sobrepostos que se separaram.

2 O cristal de dupla terminação é aquele que tem dois ápices, um em cada extremidade. Um desses ápices tem 6 lados e corresponde aos ângulos padronizados; o outro tem menos de 6 lados e não tem ângulos recorrentes.

3 São cristais com faces desenvolvidas imperfeitamente. marcas geralmente aparecem quando os cristais se formam colados uns nos outros (o que é muito comum) e/ou se sobrepõem, sendo depois separados. Esse processo deixa um negativo que contém essas marcas paralelas, mas não tem nenhuma relação com o eixo cristalográfico da peça (fig. 6). Essas estrias que não indicam o eixo cristalográfico não são perfeitamente alinhadas ou paralelas e por isso podem ser diferenciadas das estrias de crescimento.

As cinco formas elementares do lascamento de cristal de quartzo

Durante as análises do quartzo lascado no sítio arqueológico Bibocas II (Bassi 2012), identificaram-se cinco formas básicas e imprescindíveis para o lascamento do cristal de quartzo. Essas possibilidades foram descritas a partir da análise do material, tendo em vista as discussões sobre sua morfologia, facetas e ângulos. Acredito que qualquer retirada de lascas dessa matéria-prima implique necessariamente ao menos um desses procedimentos técnicos. Todo o referencial espacial se faz por meio dos eixos cristalográficos. As formas elementares de lascamento, ilustradas nas figuras 7 e 8 , são:

a. Transversal lateral: Ocorre principalmente no corpo do cristal, sendo passível de identificação por estrias no mesmo sentido do eixo tecnológico da lasca; arestas perpendiculares ao eixo tecnológico da lasca; talão de faceta de cristal com ângulo de $120^{\circ}$ entre o talão e a face externa

b. Transversal frontal: As arestas são perpendiculares ao eixo tecnológico da lasca; as facetas e arestas estão quase sempre nas bordas da lasca; se houver estrias de crescimento no talão, elas serão perpendiculares ao eixo tecnológico da lasca

c. Transversal diagonal: Transição entre o lascamento frontal e o lateral. O que define essa classificação é a análise da relação entre o eixo tecnológico da lasca e o eixo cristalográfico

d. Lascamento longitudinal: $\mathrm{O}$ eixo tecnológico da lasca coincide com o eixo cristalográfico. O talão nunca é de faceta de cristal (cortical); 
as estrias e as arestas de corpo-ápice são perpendiculares ao eixo tecnológico da lasca; as arestas de corpo e ápice-ápice coincidem com o eixo tecnológico da lasca.

e. Lascamento oblíquo: A transição entre o lascamento longitudinal e o transversal caracteriza-se por um ângulo próximo a $45^{\circ}$ entre o plano de percussão e o eixo cristalográfico.

Como ilustrado na figura 8 , considerando um cristal inteiro (1), é possivel realizar uma abertura inicial com a retirada de ápice através de lascamento transversal frontal, com ponto de impacto no corpo (2); a partir daí abrem-se outras possibilidades, como por exemplo, a retirada transversal diagonal (3); formando um ângulo favorável para lascamento transversal lateral (4). Após esta sequência, o primeiro negativo formado pela remoção do ápice serve como plano de percussão para uma retirada longitudinal (5). O cristal então é lascado (transversal frontal) (6), formando um plano de percussão favorável para negativos oblíquos (7).
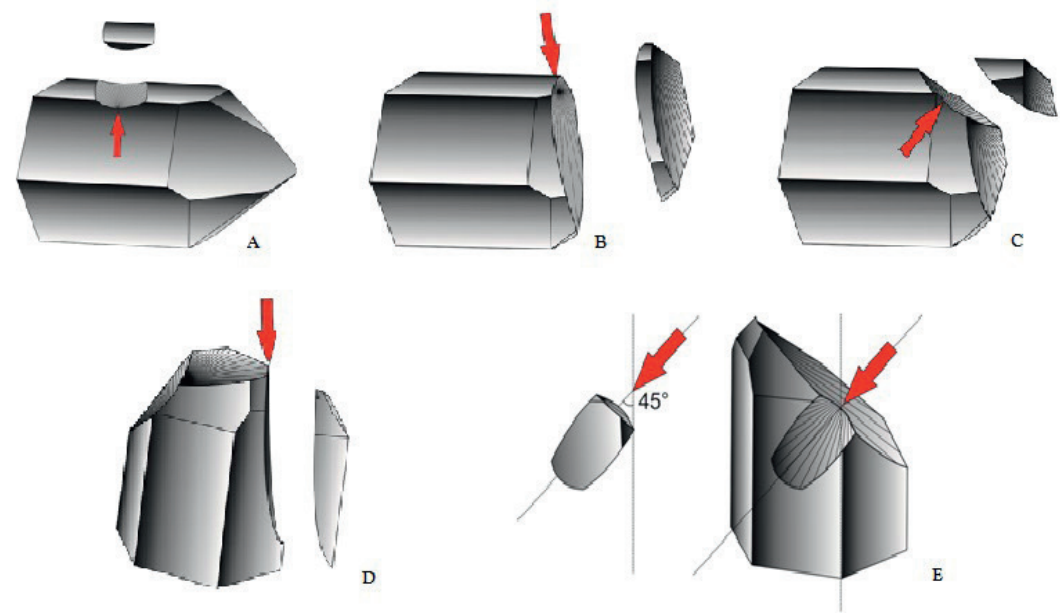

Fig. 7. Formas elementares de lascamento em cristal de quartzo. A: tansversal lateral; B: transversal frontal; C: transversal diagonal; D: longitudinal; E: obliquo.
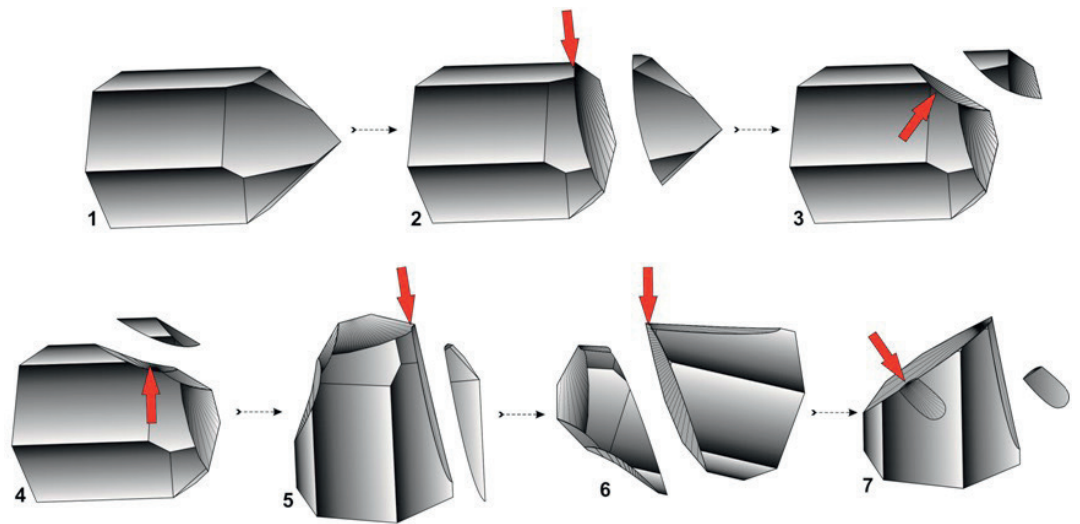

Fig. 8. Possibilidades para o lascamento do cristal de quartzo. (1): cristal inteiro; (2): abertura inicial com retirada do ápice por lascamento transversal frontal; (3): retirada transversal diagonal; (4) lascamento transversal lateral; (5) retirada longitudinal; (6) lascamento transversal frontal; (7) retiradas por lascamento oblíquo. 


\section{Percussão sobre bigorna (PSB ou bipolar)}

O lascamento sobre bigorna também pode ser analisado pela metodologia proposta neste artigo. A viabilidade depende da apresentação da coleção: se houver peças nucleiformes com ao menos uma faceta de cristal, é possível fazer uma análise diacrítica dos estigmas para identificar os gestos de lascamento e pressupor a posição do núcleo/suporte em relação ao golpe recebido.

Assim, pode-se inferir se a peça foi lascada transversal, longitudinal ou obliquamente (para este último caso, ver Prous, Souza e Lima 2014: 287-326). Além disso, também se podem distinguir as sequências de lascamento, as preferências e as ausências.

Lascamento transversal lateral e lascamento oblíquo

Alguns consideram o lascamento transversal lateral impossível, mas ele já foi reproduzido inúmeras vezes em experimentos no MHNJB-UFMG. Lascas deste tipo apresentam um ângulo de $120^{\circ}$ entre o talão e a face superior, isso é possível devido à fragilidade do quartzo e também porque, na maioria das vezes, a lasca retira completamente a faceta (fig. 9, imagens 3 e 4), o que permite "vencer" um ângulo improvável. Dessa forma, o ângulo de lascamento é inferior a $120^{\circ}$ (Isnardis e Prous, comunicação pessoal).

A figura 9 apresenta algumas das possibilidades de lascamento transversal lateral. Na imagem número 2 há uma retirada improvável devido ao ângulo de lascamento permanecer próximo de $120^{\circ}$. Nesse caso, o lascamento seria possível apenas se a morfologia do corpo do cristal fosse achatada e houvesse um recuo maior no plano de percussão, formando um talão mais largo. $\mathrm{Na}$ imagem de número 3 há uma retirada que extrai mais massa do núcleo/suporte e que prolonga-se até quase a aresta da parte inferior do hexágono. $\mathrm{Na}$ figura 4 o ângulo de percussão se aproxima muito do ângulo "ideal" de $90^{\circ}$, sendo que extrai boa parte do núcleo/suporte, formando uma abertura quase plana no hexágono.

As retiradas de lascas transversais laterais são perfeitamente possíveis, mas frequentemente devem ser acompanhadas por outras retiradas que facilitam o lascamento, como por exemplo uma retirada transversal diagonal (ver fig. 8 número 4). Um ângulo de lascamento próximo a $120^{\circ}$, em cristais de quartzo, não é completamente restritivo, uma vez que vários hábitos e formatos de corpo facilitam este tipo de lascamento. Isso não significa que qualquer cristal pode ser lascado por técnica transversal lateral, pois todo tipo de abordagem depende da apresentação do núcleo/suporte e aspectos como homogeneidade e linhas de fratura são fundamentais para o sucesso da retirada de lascas. Além disso, o prisma hexagonal pode apresentar achatamento ou alargamento em áreas do corpo, sendo a morfologia também um aspecto importante a ser considerado.

Uma outra questão muito importante sobre o lascamento oblíquo deve ser discutida: quando há percussão no ápice do cristal e a única faceta existente na lasca se encontra no talão (talão com faceta de cristal), a identificação espacial da peça pode ser feita a partir das estrias de crescimento contidas neste talão. Mas quando o cristal inteiro é considerado, a transi-

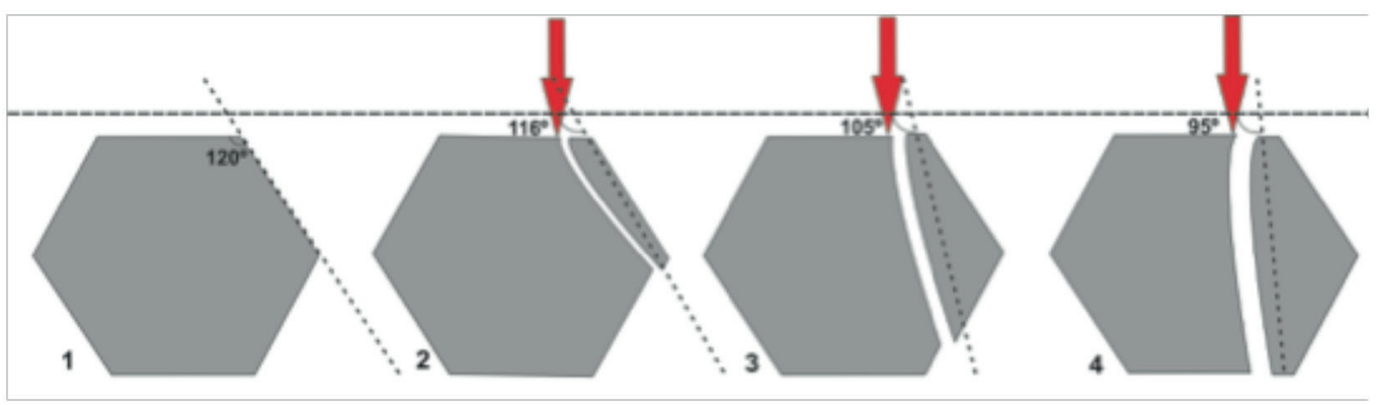

Fig. 9. Viabilidade do lascamento transversal frontal 
ção entre corpo e ápice resulta em uma quebra de angulação de $38^{\circ} \mathrm{em}$ relação ao corpo, o que leva inevitavelmente à associação com o lascamento oblíquo. Por isso é muito difícil afirmar que as lascas que possuem faceta de cristal somente no talão têm orientação longitudinal ou oblíqua, e é preciso cuidado ao se definir a orientação do lascamento, principalmente quando a única informação disponível sobre o eixo cristalográfico são as estrias de crescimento localizadas exclusivamente no talão da lasca.

Outra dificuldade sobre a identificação do lascamento oblíquo diz respeito ao ângulo de lascamento, ou seja, aquele formado entre o talão e a face inferior da lasca. Se ele se apresentar próximo a $135^{\circ}$ o lascamento provavelmente é oblíquo, e isto se explica pela posição do eixo tecnológico da lasca (sempre num plano tridimensional) em relação ao eixo cristalográfico. Porém nem sempre uma retirada oblíqua gera um ângulo de lascamento próximo a $135^{\circ}$, e esta medida deve ser utilizada apenas como mais um elemento para identificação.

\section{Jazidas e o garimpo de cristal: aspectos para a contextualização dos sítios arqueológicos}

A localização de jazidas e a forma como as rochas e minerais se apresentam são fundamentais para discutir aspectos de economia e de gestão da matéria-prima. As escolhas dos grupos pré-históricos estão atreladas a elementos que podem ser identificados e discutidos através do registro arqueológico, tais como a distribuição geográfica dos ambientes procurados e suas possíveis relações com a dificuldade de extração de matéria-prima, com as morfologias dos núcleos e suportes, com as características das rochas e minerais, etc.

A compreensão das características naturais de ocorrência do quartzo é de grande relevância para pensar nas políticas de aproveitamento das coisas e do espaço, transformadas em registro arqueológico pela agência humana. Compreender e caracterizar bem, em cada contexto, as formas naturais do quartzo, influencia diretamente as considerações feitas sobre o aproveitamento tecnológico, sobre o uso e sobre a ocupação do espaço.
Duas jazidas de cristal de quartzo foram localizadas nas proximidades do sítio arqueológico Bibocas II, denominadas localmente como Lavra das Bibocas e Lavrinha. Estas foram descritas como:

"As rochas filíticas e quartzíticas das Serras do Cabral e Espinhaço encontram-se recortadas por numerosos veios de quartzo de origem hidrotermal, como produto de preenchimento de falhas e fraturas. Também ocorrem, em menor escala, veios de quartzo atravessando sequências pelíticas da Formação Paraopeba e Grupo Macaúbas." (Engecorps 2005: 219).

\section{A Nota Explicativa da Folha Jequitai}

(SE.23-X-C-II) 1:100.000 caracteriza as jazidas de cristal desta região como:

"Os depósitos de quartzo se associam a filões hidrotermais, com no máximo $5 \mathrm{~m}$ de espessura e provavelmente relacionados à Orogenia Brasiliana, cortando rochas metapelíticas dos supergrupos Espinhaço e São Francisco." (Chaves e Benitez 2007: 34).

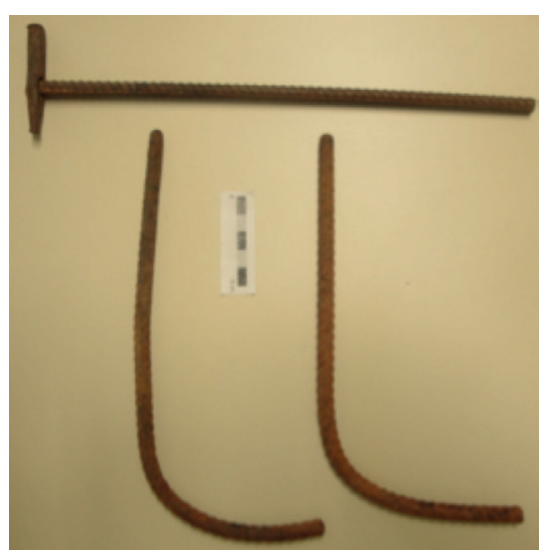

Fig. 10. O coqueirinho (na parte superior da imagem) é um pequeno martelo de metal com uma extremidade pontuda e outra quadrada; o cabo pode ser de madeira ou de vergalhão de aço. Os vergalhões dobrados (ambos na parte inferior da imagem) também são usados para lascar cristal. Fonte: Bassi (2012: 23) 
Os cristais de quartzo destas jazidas são explorados comercialmente em Jequitaí e sua extração é feita de forma manual (marretas, picaretas, pás, alavancas e marrão). Geralmente são abertos no sedimento buracos de até 4 metros de diâmetro, passando pela rocha até chegar ao veio, ou, em outros casos, são feitos cortes no perfil que podem chegar a mais de $10 \mathrm{~m}$ de altura (fig.10). Quando isto ocorre os garimpeiros seguem a linha do filão e extraem o que chamam de "custelão". Este tipo de extração gera pilhas de sedimento e rejeito, este último composto basicamente por quartzo esbranquiçado e amorfo (localmente chamado de "quartzito"), e também por cristais com muitas intrusões e por pedaços que não possuem valor agregado.

Este "quartzito" é a fonte de sílica que proporcionou a formação/crescimento de cristais em meio aquoso nas fendas, sendo o revestimento característico em que os cristais se formam. É uma rocha silicosa amorfa e acinzentada e/ou esbranquiçada, com fissuras que não interessam ao mercado atual embora os garimpeiros relatem que já houve comércio para este quartzo amorfo para utilização em indústrias e construção civil.

Outra característica importante nestas jazidas de "custelão" são as "ilhas" de cristal lascado (acumulações detríticas), geralmente localizadas em áreas de sombra. Nestes locais há uma enorme quantidade de lascas e fragmentos de cristais de todos os tipos, cores e tamanhos. É onde os garimpeiros "limpam" os cristais para agregar valor às peças, ou seja, retiram os cristais do "custelão" ou retiram partes de sílica amorfa para vender o "custelão" inteiro. Nesta atividade, que pode ser exercida nestas "ilhas" de cristais lascados ou em qualquer outra área (o sítio arqueológico Bibocas II foi um local utilizado pelos garimpeiros para lascar cristal) são usados como percutores o "coqueirinho" e/ou um pedaço de vergalhão de aproximadamente $30 \mathrm{~cm}$ de comprimento (fig. 11), dobrado em uma das pontas. Ambos são utilizados para retirar lascas com maior precisão. Este trabalho pode ser realizado por mulheres e crianças, sendo que a extração do "custelão" é exercida, quase sempre, pelos homens.

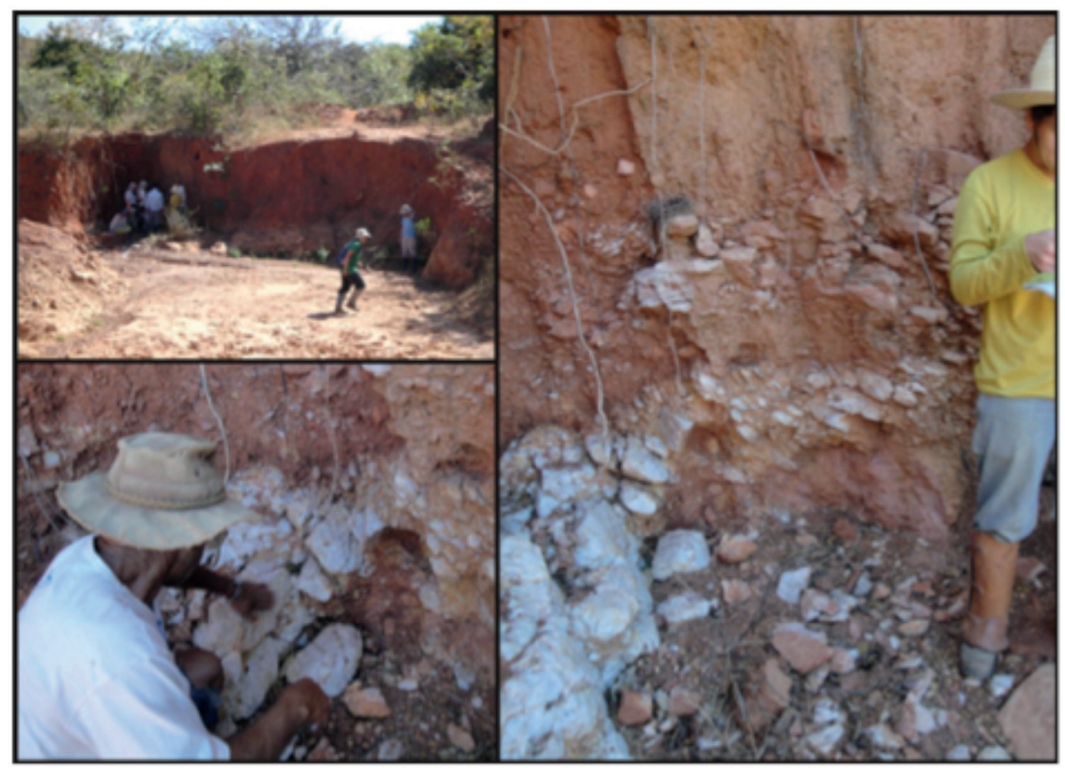

Fig 11. Jazida de quartzo das Bibocas (em atividade). Os garimpeiros fizeram um corte no barranco para seguir o filão hidrotermal. Formam-se pilhas de rejeito com sedimento e quartzo sem valor agregado. Isso é chamado localmente de garimpo de "custelão", em referência ao quartzo amorfo com cristais entremeados. 
Os garimpeiros de "custelão" fazem uma separação entre o que é quartzo e o que é cristal. O primeiro é o quartzo leitoso, o segundo é o cristal hialino e pode variar em tipos mais ou menos valiosos. O cristal de "cabelo" (rutilado) é o mais caro chegando a ser vendido por até 50 reais o quilo. Outro muito procurado, porém mais raro, é o cristal "mofado", este apresenta uma intrusão verde. Existem também os cristais de hábito do tipo Muzo e Tessim (cuja denominação local não foi registrada) que apresentam estrias de crescimento muito marcadas e protuberantes, além do "lobisomem" (com facetas escuras e ásperas, mas muito hialino por dentro, ideal para lapidar). Todas essas intrusões minerais ou morfologias específicas são características que aumentam consideravelmente o valor de venda das peças.

Todos estes tipos são mais caros, mas podem variar de preço dependendo do tamanho, formato e a forma como estão arranjados no "custelão". O cristal hialino fragmentado, sem qualquer característica que o torne especial, custa em média 10 reais o quilo. Antigamente os cristais eram vendidos para indústrias eletrônica e siderúrgica, mas atualmente os principais compradores são os intermediários que adquirem o quartzo por valores muito baixos na mão dos garimpeiros e revendem para serem lapidados em joalherias e/ou lojas de esoterismo e decoração.

Durante as campanhas de campo em Jequitaí, foi coletado quartzo lascado das áreas de garimpo. Este material está sendo analisado em trabalhos de monografia de estudantes de graduação do curso de Antropologia da UFMG e também foi alvo de um artigo (Rodet et al 2014).

No sítio arqueológico Bibocas II são raras as peças em quartzo leitoso, no entanto, este material é o mais abundante nas jazidas de quartzo da região. É possível encontrar alguns cristais dispersos em superfície, mas em geral, é necessário cavar buracos e quebrar rochas para extração do cristal hialino. Isso indica uma clara escolha dos grupos pré-históricos que ocuparam o abrigo (Bassi, 2012). Este conhecimento da gestão do quartzo, seja ele sob a forma de cristais ou não, é fundamental para se pensar o contexto arqueológico.
Conhecer este tipo de garimpo é de grande importância, pois a extração e o lascamento de quartzo permanecem até hoje como atividade importante para as pessoas que moram na região de Jequitaí. Além disso, o garimpo interage diretamente na conservação de sítios pré-históricos, pois pode sobrepor e/ou misturar o material lítico, devido à grande possibilidade de compartilhamento dos mesmos espaços e jazidas de quartzo.

Dessa forma, o conhecimento das técnicas e da localização dos garimpos atuais pode ajudar a encontrar novos sítios arqueológicos pré-históricos e contribuir para o conhecimento das formas de exploração e gestão desta matéria-prima. Através deste estudo é possível levantar mais dados e expandir as discussões sobre tecnologia lítica e gestão de matérias-primas, assim como uso e ocupação da paisagem.

\section{Comparação entre os sítios arqueológicos Bibocas II e Santana do Riacho}

As análises da escavação central do sítio arqueológico Bibocas II possibilitaram a identificação de várias abordagens de lascamento do quartzo, o que demonstra uma grande variedade de escolhas. Portanto não há uma recorrência ou repetição no lascamento do cristal, mas o que é típico desta indústria em específico é a diversidade de formas de lascamento. Esta característica diverge das publicações sobre o cristal de quartzo do abrigo de Santana do Riacho (Prous 1991: 229-274), localizado no município homônimo, no estado de MG.

A. Prous (1991) descreve as indústrias sobre cristal de quartzo de Santana do Riacho como sendo majoritariamente lascadas por PSB (percussão sobre bigorna, também conhecida como lascamento bipolar), para o autor isso acarreta num melhor aproveitamento de cristais devido ao tamanho e morfologia destes. Esta técnica tende a produzir os mesmos tipos de produtos e na mesma proporção, enquanto na debitagem por percussão direta dura (PDD, também conhecida como unipolar) a morfologia do cristal limitaria as possibilidades de abordagem. Segundo Prous, a dificuldade de debitagem 
lateral leva a iniciar o lascamento pelo ápice ou raiz, criando lascas com gume de faceta sem a necessidade de "descorticar" a peça. Outra característica importante é a raridade dos cristais ou seixos maiores que $5 \mathrm{~cm}$ no sítio.

São descritos quatro processos de lascamento baseados na análise de lascas e núcleos (nuclei) em Santana do Riacho: os nuclei semi piramidais, resultado de quando o lascamento se inicia pelo ápice ou pela raiz; os cristais grandes (raros), retira-se uma faceta lateral e posteriormente são retiradas lascas (laterais) transversais; o lascamento a partir de ambas as extremidades, com dois planos de percussão opostos; e por fim os núcleos poliédricos, com mais de dois ângulos de percussão, caracterizando os blocos residuais de debitagem bipolar. Há, também, as lascas com dorso cortical indicando uma debitagem transversal (frontal e/ou diagonal) em gomos ou fatias, sendo raros os nuclei correspondentes a esta abordagem.

As formas de lascamento do cristal identificadas em Santana do Riacho são mais associadas à PSB (bipolar), sendo a PDD menos recorrente no sítio, dessa forma não há exploração recorrente das cinco formas elementares do lascamento do cristal presente no abrigo Bibocas II. Em Jequitaí ocorre o contrário, a PDD é predominante, principalmente nos níveis mais antigos (VI e $\mathrm{V}$ inferior), isso permite uma ampla variação da utilização da morfologia dos cristais, demonstrando que o que foi considerado impraticável em Santana do Riacho acontece com frequência em Jequitaí. Ou seja, há lascamento lateral com talões de faceta de cristal e outras formas muito variáveis de aproveitamento desta matéria-prima. Portanto, não acreditamos que a morfologia do cristal limita as possibilidades de abordagem, muito pelo contrário, ela as amplia e permite conjugar com muita eficiência as cinco formas elementares do lascamento de cristal, podendo ser infinitamente aproveitadas, criando planos e superfícies de percussão, transformando as morfologias e ângulos dos núcleos ou suportes.

O que antes era considerado limitador, agora deve ser visto como novas possibilidades, que vão muito além de ângulos considerados "ruins" para lascar.
Por fim, a escavação central do sítio arqueológico Bibocas II apresenta uma ampla variação das cinco formas elementares do lascamento de cristal, no entanto, não há neste momento, nenhuma indicação quantitativa ou qualitativa que indique sistematização ou métodos de lascamento nesta matéria-prima. O que se sabe é que todas as possibilidades de lascamento estão presentes de forma aparentemente aleatória na estratigrafia. Isto não significa que não existam métodos sistemáticos por trás da gestão tecnológica dos cristais, mas que ainda não temos dados suficientes para afirmar tal proposição.

\section{Considerações finais}

A recorrência natural de ângulos entre as facetas do cristal permite, em alguns casos, identificar imediatamente a posição da lasca no suporte original e mapear algumas das formas como o quartzo foi lascado e, quando possível, os métodos mais recorrentes. A análise desses ângulos constantes entre as facetas dos cristais pode ensejar novas interpretações sobre a gestão humana do quartzo em sítios arqueológicos.

Na prática, é difícil medir os ângulos, ainda mais numa coleção de pequenas lascas, o que dificulta a aplicação dos procedimentos necessários para chegar a uma medida exata proposta pela cristalografia. Nem sempre é possível medir satisfatoriamente os ângulos, pois algumas lascas apresentam facetas correspondentes muito pequenas, devido ao processo de lascamento. Na coleção do sítio Bibocas II, casos assim foram descritos, mas excluídos das sínteses qualitativas e separados para possíveis referências.

Essa metodologia de análise pode ser aplicada a qualquer coleção arqueológica que apresente cristais com facetas, de modo que é possivel identificar as escolhas mais recorrentes no lascamento do cristal e fazer um levantamento estatístico das preferências.

$\mathrm{Na}$ arqueologia, os ângulos recorrentes em cristais não devem ser interpretados como dados inequívocos, mas como instrumentos auxiliares para descrever tendências ou métodos de lascamento. Como os suportes do 
quartzo hialino são conhecidos - são prismas hexagonais -, é possível discernir sequências de lascamento, e, mesmo que não se identifiquem métodos ou padrões na forma de lascar, podemos ver elementos que são comumente ignorados pelos pesquisadores: procedimentos técnicos que não foram adotados, escolhas de lascamento que não são cogitadas por ser consideradas "absurdas" pelos arqueólogos e as possibilidades que foram exploradas, sejam elas sistemáticas ou não.

Além disso, essa metodologia abre novas possibilidades de análises para qualquer coleção que tenha cristais com algumas facetas, independentemente do número de lascas, núcleos ou instrumentos. Mas, como já foi dito, tudo isso depende da análise do contexto, no sentido mais amplo do termo.

\section{Agradecimentos}

Agradeço à professora Maria Jacqueline Rodet, pela orientação e pelos ensinamentos desde o meu início na arqueologia; ao professor Andrei Isnardis, pela co-orientação, pelas discussões e pelos esclarecimentos; ao professor André Prous, pelo suporte e pelo incentivo, além das críticas construtivas ao trabalho; ao professor Marcelo Fagundes, que também teve uma importante participação no amadurecimento do texto e das ideias propostas neste artigo; à professora Sibeli Aparecida Viana, cujas contribuições foram importantes pra o texto; e a Marcony Lopes Alves, companheiro de moradia que ajudou na revisão do texto e teceu comentários que foram prontamente assimilados.

BASSI, L.F. Methodology for technological analysis in quartz crystals. R. Museu Arq. Etn., 25: 105-117, 2015.

Abstract: This article covers a topic discussed in the master's thesis (Basssi, 2012) on technological analysis of the quartz crystal, from the archaeological site Bibocas II in Jequitaí MG. Through the analysis of the axes in the natural crystal facets is possible to identify important elements on the knapping process. Thus, the technologic analysis of the collection by the proposed approach allows identification of the location of the core / blank, in addition to the description of possible knapping methods.

Keywords: Lithic Technology. Quartz Crystal. Methods and Techniques of knapping.

\section{Referências Bibliográficas}

Akhavan, A.C. 2012. The Quartz Page. Disponivel em <http://www.quartzpage. de/about.html>. Acesso em: 27 nov. 2015.

Bassi, L.F. 2012. Tecnologia lítica: análise diacrônica dos níveis mais antigos do sítio arqueológico Bibocas II, Jequitaí-MG. Belo Horizonte: Universidade Federal de Minas Gerais.

Chaves, M.L.C.; Benitez, L. 2007. Programa Geologia do Brasil: nota explicativa da folha Jequitaí. Companhia de Pesquisa de Recur- 
sos Minerais-CPRM. Serviço Geológico do Brasil, Minas Gerais.

Dana, J.D.; Hurlbut, C.S. 1974. Manual de Mineralogia. Trad. R. R. Franco. Rio de Janeiro: Livros Técnicos e Científicos. 4 v.

Engecorps. 2005. Estudo de impacto ambiental: Projeto Jequitaí. Brasília: Codevasf.

Prous, A. 1991. Indústria lítica de Santana do Riacho: tecnologia, tipologia e traceologia - Os instrumentos lascados. Arquivos do Museu de História Natural da Universidade Federal de Minas Gerais, 12: 229 - 274.

Prous, A., Souza, G., Lima, A. 2014. A importância do lascamento sobre bigorna nas indústrias líticas do Brasil. Arquivos do Museu de História Natural e Jardim Botânico da Universidade Federal de Minas Gerais, 21: 287-326.

Rodet M.J.; Duarte-Talim, D.; Abrahan, L. 2013. Experimentações da percussão sobre bigorna no cristal de quartzo. Revista Espinhaço 2:147-152.

Rodet, M.; Duarte-Talim, D.; Nolasco, R.C.; Silva, A.L.N. 2014. Da pré-história aos garimpeiros, uma análise tecnológica das indústrias líticas de quartzo. Estudos Contemporâneos na Arqueologia 1. Indústrias líticas na América do Sul abordagens teóricas e metodológicas, Recife: UFPE. 